\title{
Amizade política e comunhão cristã:
}

um diálogo entre Hannah Arendt e Dietrich Bonhoeffer

\section{Karina Fonseca Soares Rezende}

Karina Fonseca Soares Rezende é mestranda na linha de História e Culturas Políticas do Programa de Pós-Graduação em História da Universidade Federal de Minas Gerais (UFMG). O presente trabalho foi realizado com apoio da Coordenação de Aperfeiçoamento de Pessoal de Nível Superior Brasil (CAPES). Email: kaa.rezende@gmail.com.

Resumo: O presente artigo pretende discutir e relacionar dois conceitos filosóficos e teológicos: a comunhão cristã e a amizade política nos pensamentos de Hannah Arendt e Dietrich Bonhoeffer. Pretendemos compreender como o conceito de responsabilidade é um elo central na discussão de Arendt sobre amor mundi e o conceito de Bonhoeffer de Igreja e responsabilidade cristã no mundo. Desejamos perceber como o entendimento desses intelectuais de responsabilidade individual é fundamental para as ações dos seres humanos no mundo público.

Palavras-chave: Hannah Arendt; Dietrich Bonhoeffer; responsabilidade política.

\section{Political friendship and christian community:}

a dialogue between Hannah Arendt and Dietrich Bonhoeffer

\begin{abstract}
The current article intends to discuss two philosophical and theological concepts: the christian community and political friendship according to the thoughts of Hannah Arendt and Dietrich Bonhoeffer, and also relate them. We intend to understand how the concept of responsability is primary to connect Arendt's understanding of amor mundi and Bonhoeffer's concept of church and the christian responsability in the world. We want to understand how their perception about the individual responsability is important to make the human being's actions in the public world.
\end{abstract}

Keyword: Hannah Arendt; Dietrich Bonhoeffer; political responsability. 
Como relacionar um saber que dirige seus olhos e esforços para compreender os céus e as divindades com as responsabilidades cotidianas que são impostas aos indivíduos? Seria necessário "mundanizar" a teologia? Ou divinizar o próprio mundo? Essas indagações são discussões contemporâneas - e relevantes - dentro de seminários teológicos e nos escritos de importantes intelectuais da área nos últimos séculos (ao menos). A Teologia Pública que, nas palavras de Jürgen Moltmann ${ }^{1}$ pensa a relevância pública da teologia, reflete acerca do alcance do discurso teológico e pastoral fora dos muros da Igreja. É uma visão nãocontemplativa ou passiva de mundo mas, sim, uma compreensão do indivíduo que, ao mesmo tempo existe em suas práticas e crenças e existe, também, em um mundo real, onde ouvir um sermão que traz a vivência concreta em suas palavras - seja por aspectos sociais, políticos e culturais - é um diálogo com seu próprio cotidiano.

Localizar o cristão como um ser humano em um espaço político traz, todavia, uma série de implicações. A principal delas e central para este artigo é: os cristãos tem responsabilidade no mundo? Se sim, qual seria esta? Tais questionamentos nos parecem bastante incômodos no século XX e, até mesmo, no século XXI tendo em vista as disputas narrativas dentro da própria teologia. Compreende-se, nesta leitura, que a perspectiva teológica das pessoas possui uma grande influência em suas percepções políticas. Tais compreensões podem influenciar o posicionamento de um indivíduo, como no caso onde uma visão escatológica ou até mesmo apocalíptica de mundo pode ser apropriada pelos sujeitos como forma de não se verem responsáveis ou agentes de mudança no mundo onde estão inseridos. Não há, todavia, um determinismo pré-estabelecido na relação entre crença religiosa e posicionamento político. Porém, isso não nos impede de perceber que a teologia traz chaves de leitura e um papel político no mundo.

Essa relação teologia-política fica evidente ao conhecermos a figura de Dietrich Bonhoeffer, um dos grandes nomes da teologia alemã não somente por seus escritos, mas também por sua atuação político-religiosa contra o nazismo. Sua visão acerca da necessidade de ação do cristão no mundo público e seu comportamento frente ao Partido NacionalSocialista sintetizam a relação entre pensamento religioso e pensamento político. Para o texto em questão, examinaremos um conceito fundamental para a elaboração da ideia bonhoefferiana de responsabilidade cristã no mundo: o conceito de comunhão. A ideia de agir

\footnotetext{
${ }^{1}$ Jürgen Moltann é um dos mais renomados teólogos protestantes com obras como Teologia da Esperança e $O$ Deus Crucificado. O teólogo, em suas recentes obras, reflete a ação do cristão fora dos muros institucionais da igreja e dos seminários teológicos.
} 
com e para com o outro como um dos preceitos fundamentais da teologia encontra diálogo, também, com escritos filosóficos desde Aristóteles. O homem, só, o que pode fazer? O agrupamento, a união entre iguais e diferentes, é a ideia fundadora do mundo público desde a Antiguidade Clássica.

Assim sendo, uma das maiores filósofas contemporâneas é responsável por apresentar um conceito de política que colide com a tradição de pensamento vigente até então e que coloca a responsabilidade e a necessidade de agir com o meu próximo como cernes de sua filosofia. As vastas obras de Hannah Arendt trazem a ideia de amizade política como aquilo que quebra a barreira do âmbito privado e existe por haver uma consciência de responsabilidade comum com o mundo onde vivemos. As obras de Arendt, partindo de Origens do Totalitarismo, tentam compreender a questão do mal na modernidade e as relações dos indivíduos consigo e com o mundo no que diz respeito às ideias de culpa e responsabilidade.

É fundamental estabelecer essa discussão tendo em vista que ambos experienciaram o totalitarismo e são intelectuais que, em seus diferentes campos de atuação, refletiram acerca da destruição dos laços humanos pelo movimento totalitário. Em exílio durante boa parte da década de 1930, Arendt sentiu as privações da liberdade na sua carreira acadêmica e profissional, além de ser obrigada a abandonar seu lar. Dietrich Bonhoeffer, em consequência de sua resistência político-religiosa, tanto discursiva quanto conspiratória, foi vítima de investigações e perseguições ao longo dos anos de 1930 e assassinado no fim do regime nazista.

Pensar o contexto de formulação dos conceitos de amizade politica e comunhão cristã por essas duas figuras que experienciaram o nazismo de diferentes formas é essencial para compreendermos o impacto do pensamento no momento de sua formulação e seu legado para a posteridade. Entendemos a elaboração dessas categorias de análise como uma intervenção em sua época. ${ }^{2}$ Intervenção experienciada por indivíduos de uma classe intelectual renomada da Alemanha: Dietrich Bonhoeffer, membro de uma família de grande renome especialmente devido ao trabalho de psiquiatria de seu pai, Karl Bonhoeffer e Hannah Arendt, filósofa com redes de sociabilidade intelectual bem estabelecidas na Alemanha e que, com o fim do Terceiro Reich, se torna mundialmente conhecida pelas suas reflexões sobre o totalitarismo.

\footnotetext{
${ }^{2}$ Quentin Skinner é um dos grandes nomes do campo da História das Ideias para nossa discussão acerca dos impactos dos escritos em uma época e do contexto na elaboração de conceitos e pensamentos políticos e religiosos.
} 
Fazer um diálogo entre os conceitos de comunhão cristã de Dietrich Bonhoeffer e amizade política de Hannah Arendt, tendo como eixo a noção de responsabilidade pelo mundo, apresenta-se como uma discussão muito relevante ao pensarmos as noções vinculadas no senso comum sobre o que é ou não participação política e sobre nosso lugar, enquanto cidadãos, nessa discussão. O descrédito na política e na ação no mundo público, presente, inclusive, no discurso de muitos políticos, é primordial nas tentativas de desmobilizar qualquer forma de ação política na sociedade.

Os conceitos de amizade e comunhão que serão apresentados são, por outro lado, mobilizadores de ações em prol do bem comum assim como princípios para a associação no mundo público. Partindo dessa discussão, somos capazes de refletir como na contemporaneidade a ideia de que todos os indivíduos tem responsabilidade no mundo político no qual fazem parte não está colocada em pauta - apenas em momentos muito específicos, como em eleições. Essa falta de uma cultura democrática e republicana faz com que muitos indivíduos não compreendam que podem exercer a política no cotidiano, algo para além da política institucionalizada. Mais do que isso: enquanto cidadãos, tem essa responsabilidade.

As reflexões propostas não pretendem sintetizar ou dar conta da discussão teológica e filosófica - que também são fundamentalmente políticas - de Bonhoeffer e Arendt. Pretendese, entretanto, além de compreender as nuances e possibilidades de diálogo entre o pensamento dessas duas figuras, analisar como as compreensões de conceitos fundamentais no campo da teologia e da política abrem caminho para novas discussões - tanto na academia quanto fora dela - sobre o entendimento e a atuação dos indivíduos na esfera pública e privada.

\section{"Alcançar humanidade em um mundo desumano": Hannah Arendt e a amizade política como amor mundi}

A correlação que Hannah Arendt faz entre política e liberdade é o fundamento de todo o pensamento político da filósofa. Política é, em sua essência, liberdade. ${ }^{4}$ Em um espaço onde a liberdade é cerceada, a política deixa de ser exercida. Para compreender, portanto, a relevância do conceito de amizade política para a filósofa se faz necessário entender como este integra sua reflexão sobre política. Arendt não faz a correspondência de política com

\footnotetext{
${ }^{3}$ Trecho das reflexões da filósofa sobre o poeta e filósofo Lessing. Cf ARENDT, Hannah. Homens em Tempos Sombrios. Tradução de Denise Bottmann. São Paulo: Companhia das Letras, 1987, p. 32.

${ }^{4}$ ARENDT, Hannah. A dignidade da política. Rio de Janeiro: Relume-Damará, 1993, p. 161.
} 
dominação. Em consequência disso, considera política como uma ação que pode ocorrer tanto em espaços institucionalizados ou não e que ocorre, somente, em junção com o outro. Na coletânea Entre o Passado e o Futuro, a filósofa afirma que

\footnotetext{
A liberdade, ou o seu contrário, experimenta-se com o outro e não em relação consigo mesmo. Os homens são livres - diferentemente de possuírem o dom da liberdade - enquanto agem, nem antes, nem depois, pois ser livre e agir é a mesma coisa. ${ }^{5}$
}

O pressuposto que a liberdade - ou seja, a própria política - é experienciada a partir da relação do eu mais alguém é essencial para que a autora defenda a ideia de que os indivíduos devem se associar na esfera pública. Em A Condição Humana, a autora se debruça sobre questões relacionadas a constituição do ser e a sua relação com o outro e defende que o espaço público é um espaço onde a liberdade pode aparecer, através da associação dos indivíduos, e onde esses indivíduos podem, em conjunto, construir eles mesmo o poder.

Para que esse exercício do poder seja, de fato, efetivo, deve haver espaço na esfera pública para que a política - como ação - seja exercida pelos cidadãos. Em obras como Origens do Totalitarismo e seus ensaios publicados após sua morte, Arendt mostra como os campos de concentração tentam massificar e desumanizar o humano, na tentativa de expurgar toda e qualquer reação, espontaneidade e singularidade dos indivíduos. ${ }^{6}$ A tentativa de retirar do homem o mundo comum faz com que os indivíduos sejam isolados do mundo. Segundo a filósofa, a solidão, em si, está presente na existência humana. $\mathrm{O}$ ato de pensar, por exemplo, é um ato que é feito por mim na companhia de mim mesma. É um momento onde, por opção, os indivíduos se resguardam no mundo privado. O isolamento, por outro lado, é uma das fundamentações dos regimes totalitários onde, além de retirar o homem de seu mundo comum e retirar o mundo comum do próprio homem, o ser humano é despersonificado ao ponto de deixar de ter sua própria companhia e ser isolado de si mesmo.

Zygmunt Baumann, em sua obra Amor Líquido, define que a compreensão cristã "amar ao próximo como a ti mesmo" pressupõe a relação do indivíduo com seu próprio eu. Este é constituído, essencialmente, a partir da minha relação com o outro. Segundo Baumann, "para termos amor-próprio, precisamos ser amados. A recusa do amor - a negação do status de objeto digno do amor - alimenta a autoaversão. O amor-próprio é construído a partir do amor

\footnotetext{
${ }^{5}$ ARENDT, Hannah. Entre o Passado e Futuro. 6a ed. São Paulo: Perspectiva. P. 196.

6 ARENDT, Hannah. Origens do totalitarismo: antissemitismo, imperialismo, totalitarismo. Rio de Janeiro: Companhia das Letras, 2013; ARENDT, Hannah. Compreender: formação, exílio e totalitarismo; ensaios (19301954). Rio de Janeiro: Companhia das Letras, 2008, p. 375.
} 
que nos é oferecido por outros."7 . Tendo em vista essa reflexão, é possível ler o totalitarismo como uma forma de, ao retirar o indivíduo do convívio e da relação afetuosa com seus pares, retira-lo do convívio e da relação afetuosa consigo mesmo. Se o amor próprio é uma força necessária para se "agarrar a vida", estabelecer um vínculo com o outro se apresenta como essencial para a manutenção do próprio eu no mundo público.

O conceito de amizade política arendtiano se insere dentro dessa perspectiva. O que Hannah Arendt compreende por amizade não se reduz ao uso corriqueiro da palavra. Não é a relação minha com meu semelhante em minha casa, discutindo assuntos particulares. É ter consciência da minha responsabilidade no mundo e que minha relação com o outro deve ser em ação e para com o mundo que partilhamos. Em A Condição Humana, ela demonstra que, quando os assuntos são tratados na esfera pública, são ressignificados. É importante, para isso, compreender o que Arendt chama de mundo ou espaço público.

\begin{abstract}
O termo 'público' significa o próprio mundo, na medida em que é comum a todos nós e diferente do lugar que nos cabe dentro dele. [...]. [Este mundo] tem a ver com o artefato humano, com o produto de mãos humanas, com os negócios realizados entre os que, juntos, habitam o mundo feito pelo homem. ${ }^{9}$
\end{abstract}

Sendo o mundo público o local onde as relações humanas se constroem, se estabelecem, se rompem, se reinventam, é nesse espaço, pautado pelo nós, que a política pode ocorrer. Essa categoria aparece como uma forma de associação essencialmente humana "propiciadora de um espaço onde os homens participam como um 'quem' e não como coisas ${ }^{10}$.

Apesar de ser uma especificidade humana, a amizade não pode ser considerada algo intrínseco aos seres humanos. Em Homens em Tempos Sombrios, a filósofa faz um passeio pela biografia de homens e mulheres que viveram em espaços e tempos sombrios e, já no primeiro capítulo, apresenta uma reflexão acerca da amizade. Arendt faz uma pontual diferença entre compaixão e amizade ao justificar o porquê de nascer humano não o faz, necessariamente, ter humanidade. A compaixão, segundo ela, é algo da espécie humana e aparece em sua maioria em momentos de adversidade ou sofrimento do outro. Esse sentimento se diferencia da amizade pela maneira como esse se dá: de forma passiva. A

\footnotetext{
7 BAUMAN, Zygmunt. Amor líquido: sobre a fragilidade dos laços humanos. Rio de Janeiro: Jorge Zahar Editor, 2004, p. 102.

${ }^{8}$ Ibidem p. 101.

${ }^{9}$ ARENDT, Hannah. A Condição Humana. Tradução de Roberto Raposo. Rio de Janeiro: Forense, 1983 , p.62.

10 ALVES AGUIAR, Odílio. A amizade como amor mundi em Hannah Arendt. O que nos faz pensar, [S.l.], v. 19, n. 28, p. 131-144, dec. 2010. ISSN 0104-6675. Disponível em: <http://www.oquenosfazpensar.fil.pucrio.br/index.php/oqnfp/article/view/315>. Acesso em: 31 jan. 2019, p. 139.
} 
compaixão sente a dor do outro mas isso não necessariamente fará com que o indivíduo aja no mundo onde está inserido. A amizade, em contrapartida, prevê a consciência de responsabilidade e cuidado com o mundo. Essa é a noção fundamental para o conceito arendtiano de amor mundi onde a minha compreensão de pertencimento ao mundo está vinculada à ideia deste como um espaço plural. Eu, ligado a outros, sou capaz e tenho a responsabilidade de exercer a liberdade. Ou seja, a política.

Essa forma de participação no âmbito público a partir da relação com o outro é fundamentalmente estabelecida pela ação e pela palavra. $\mathrm{O}$ indivíduo age e fala no mundo público porque se vê como responsável por este. Percebe-se, portanto, a centralidade da palavra - e da palavra compreendida como ação - como forma dessa amizade política se materializar no mundo. Arendt afirma que

[...] o mundo não é humano simplesmente por ser feito por seres humanos, e nem se torna humano simplesmente porque a voz humana nele ressoa, mas apenas quando se tornou objeto de discurso. Por mais afetados que sejamos pelas coisas do mundo, por mais profundamente que possam nos instigar e estimular, só se tornam humanas para nós quando podemos discuti-las com nossos companheiros. ${ }^{11}$

A relevância política da amizade está, portanto, na potência de ação que ela tem no mundo. A amizade, dessa maneira, é uma condição para a ação humana no mundo público. E o conceito de responsabilidade é inerente ao conceito de amizade compreendido por Hannah Arendt. Um trecho que auxilia na articulação do conceito de responsabilidade com a própria existência humana está em uma de suas coletâneas de textos, o livro Compreender. Nele, Arendt afirma

Pois a ideia de humanidade, quando despida de qualquer sentimentalismo, acarreta a gravíssima consequência de que os homens, de uma forma ou de outra, devem assumir a responsabilidade por todos os crimes cometidos pelos homens e que todas as nações partilham o ônus do mal cometido por todas as outras. $^{12}$

A responsabilidade é essa compreensão de que, por sermos humanos, somos potencialmente capazes de produzir o mal e que os produtores ou colaboradores do mal são inteiramente humanos. Esses indivíduos, no entanto, são culpados pelas suas ações. Para ela, a ideia de culpa coletiva se apresenta como falácia pois, na máxima, se todos são culpados,

\footnotetext{
${ }^{11}$ ARENDT, Hannah. Homens em Tempos Sombrios. Tradução de Denise Bottmann. São Paulo: Companhia das Letras, 1987, p. 33.

12 ARENDT, Hannah. Compreender: Formação, exílio e totalitarismo. Ensaios (1930-1954). Rio de Janeiro: Companhia das Letras, 2008, p. 160.
} 
ninguém o é. Denota uma ideia da culpa flutuante ${ }^{13}$. Ter consciência da responsabilidade - e não culpa - que todos os seres humanos carregam consigo e a necessidade da minha ação responsável no mundo por eu fazer parte dessa comunidade é pressuposto fundamental para a compreensão do conceito de amizade política que a filósofa propõe.

\title{
“A Igreja só é Igreja quando está aí para os outros" ${ }^{14}$ : responsabilidade e comunhão cristã em Dietrich Bonhoeffer
}

A biografia de Dietrich Bonhoeffer é, ao menos, singular. Pastor luterano de uma família prestigiada na Polônia e Alemanha, Bonhoeffer optou pela faculdade de teologia muito novo. Em seu estudo de doutorado completo em 1927, Sanctorum Communion, começa a desenvolver parte do seu pensamento teológico sobre a Igreja que a define como a materialização da presença de Deus na terra. Exercendo o pastorado na Alemanha, se manifestava constantemente sobre questões políticas especialmente através de suas prédicas. Em um sermão sobre o dia da Reforma Protestante, ele afirma que

\begin{abstract}
hoje, entre as milhares de fanfarras que revelam uma Alemanha em estado terminal, se podem ouvir também as outras que anunciam ao mundo a morte da igreja. A Alemanha que tem medo de seu futuro tenta criar coragem através de grandes palavras de todo tipo, ditas em voz alta - para que elas afugentem o medo da morte. ${ }^{15}$
\end{abstract}

As percepções negativas de Bonhoeffer acerca dos nazistas, apesar de terem uma grande preocupação com a interferência da ideologia na comunidade cristã ${ }^{16}$, não se limitavam a esse aspecto. Logo no dia da posse do Führer, Bonhoeffer proclamou em uma rádio o discurso $O$ Conceito Alterado de Führer da Nova Geração ${ }^{17}$ onde faz uma alerta sobre o perigo de

\footnotetext{
${ }^{13}$ ARENDT, Hannah; KOHN, Jerome. Responsabilidade e julgamento. São Paulo: Companhia das Letras, 2004, p.79.

${ }^{14}$ Uma das obras centrais no Brasil que relaciona o pensamento de Dietrich Bonhoeffer com a Teologia Pública e a responsabilidade no mundo é o livro do teólogo Carlos Caldas Dietrich Bonhoeffer e a teologia pública no Brasil. Na segunda parte da obra, o autor identifica esse trecho no volume 8 da coleção Dietrich Bonhoeffer Work. Cf BONHOEFFER, Dietrich. Dietrich Bonhoeffer's Letters and Papers from Prison, vol.8, Minneapolis: Fortress Press, 2010, p. 560.

${ }^{15}$ BONHOEFFER, Dietrich. Prédica no dia da Reforma. In MALSCHITZKY, Harald. Prédicas e Alocuções, São Leopoldo: Editora Sinodal, 2007, p. 45.

${ }^{16}$ A ascensão do grupo político teológico Cristãos Alemães e a sua disseminação pelas igrejas na Alemanha se tornou uma preocupação para pastores que não compactuavam com o ultranacionalismo e a ideia de raça ariana dos nazistas. Esse movimento teológico e religioso liberal pró-nazista foi um importante núcleo de disseminação de ideias antissemitas nas práticas, discursos e dogmas da Igreja Protestante de então. Cf BERGEN, Doris L. Twisted cross: the German Christian movement in the Third Reich. Chapel Hill: Univ of North Carolina Press, 2000

${ }^{17}$ BONHOEFFER, Dietrich. Dietrich Bonhoeffer Work Vol. 12: Berlin 1932-1933. Minneapolis: Fortress Press, 2009, p.269-270.
} 
admiração exacerbada a qualquer liderança. Percebe-se, portanto, que a postura de Bonhoeffer desde o princípio não foi passiva ao momento político que vivia.

É fundamental ter em mente esses aspectos biográficos para compreender a formação de seu pensamento teológico e, mais especificamente, da importância dos conceitos comunhão e responsabilidade em suas obras. Nos anos que antecederam o início da Segunda Guerra Mundial e ao aprisionamento e exterminação de judeus nos campos de concentração, Bonhoeffer circulou pela Alemanha e por outros países, como a Inglaterra, denunciando a situação da Igreja na Alemanha e a própria política de então.

Em 1935, ao retornar de um período de quase dois anos de estadia em Londres, Bonhoeffer funda, na cidade de Finkewalde, seu seminário teológico vinculado ao grupo de oposição às interferências nazistas nas congregações protestantes, a Igreja Confessante ${ }^{18}$. Seu seminário teológico era um apêndice radical desse grupo onde ele se demonstrava como exceção dentro da comunidade protestante por contestar as bases ideológicas do regime nazista apresentando-se, portanto, como uma minoria radica $1^{19}$. $\mathrm{O}$ seminário durou até o ano de 1937 quando foi fechado pela Gestapo. Esse período foi fundamental para que Bonhoeffer elaborasse com mais profundidade seu conceito de comunhão cristã e a responsabilidade pelo outro.

Em 1938, logo após o fechamento de seu seminário e o aprisionamento de vários alunos, Bonhoeffer vai para a casa de alguns parentes na cidade de Göttingen onde escreveu o que viria ser um clássico devocional, o Vida em Comunhão. É nessa obra onde o autor sintetiza o que compreende por comunhão cristã, assunto que já era tratado desde sermões no início dos anos 1930 e que continuaria sendo discutido em obras posteriores, como Ética e Resistência e Submissão. O que seria, pois, estar em comunhão uns com os outros?

Em sua tese de doutorado, Bonhoeffer define a Igreja "não como uma entidade histórica ou uma instituição, mas Cristo existindo como comunidade eclesial" ${ }^{20}$. Essa visão da Igreja como a materialização da presença de Cristo é eixo importante para a elaboração do

\footnotetext{
${ }^{18}$ A Igreja Confessante foi um grupo formado em 1934 com o intuito de combater às interferências do governo nazista nas igrejas protestantes. Teve, como uns dos seus principais membros, Karl Barth - seu fundador -, Martin Niemoller e Dietrich Bonhoeffer. Cf BARNETT, Victoria. For the Soul of the People: Protestant protest against Hitler. Oxford: Oxford University Press, 1998, p. 47-49.

${ }^{19} \mathrm{O}$ conceito de minoria radical é elaborado pelo historiador Robert Ericksen ao analisar os casos de protestantes dentro da igreja que se prontificaram a contestar o regime nazista em si. Cf ERICKSEN, Robert P. A Radical Minority: Resistance in the German Protestant Church. In: NICOSIA, Francis R.; STOKES, Lawrence D. (Org.). Germans against Nazism: nonconformity, opposition and resistance in the Third Reich: essays in honour of Peter Hoffmann. New York: Berg Publishers Ltd, 1990.

${ }^{20}$ METAXAS, Eric. Bonhoeffer: pastor, mártir, profeta, espião. São Paulo: Mundo Cristão, 2011, p.61.
} 
pensamento do teólogo do dever da Igreja de assistir ao próximo no mundo. Se a Igreja é Cristo na terra, qual foi a relação de Cristo com o mundo? Em Resistência e Submissão, Bonhoeffer fala da importância de enxergar a história do mundo "a partir de baixo, da perspectiva dos excluídos" 21 . Segundo ele, é necessário deslocar a ideia do mundo visto de cima, do lugar do vencedor e de um prisma individualista para uma exploração contemplativa ativa do mundo. Em várias obras e sermões, Bonhoeffer reconhece Cristo no lugar do sofredor, do oprimido; não do lado vencedor da história. É um "Deus sofredor, lutador e moribundo" $" 22$. O cristão, dentro dessa perspectiva, deve dar suporte àqueles que necessitam, sem distinção. Segundo ele

\begin{abstract}
Não somos Cristo, mas se quisermos ser cristãos, importa que participemos da grandeza de coração de Cristo por meio da ação responsável, que com liberdade aproveita a oportunidade e se expõe ao perigo [...]. A espera passiva e a assistência indiferente não são atitudes cristãs. Não são as experiências no próprio corpo que chamam a pessoa cristã a agir e a compadecer-se, mas as experiências no corpo dos irmãos, pelos quais Cristo sofreu. ${ }^{23}$
\end{abstract}

Percebe-se, portanto, que o modelo de um Cristo ter um comportamento ativo com o próximo e se colocar na posição de sofrimento desse indivíduo é fundamental para a elaboração dessa teologia focada no outro. Bonhoeffer pressupõe, no entanto, que para que a relação da pessoa cristã com o mundo se estabeleça é necessária a comunhão entre os próprios cristãos.

Em um sermão de 1931, Bonhoeffer afirma que

quem encontrou Deus também encontra seu irmão, ele vê o rosto do irmão como se visse o rosto de Deus. Quem não encontra o irmão também não encontra Deus. Para isso Deus se tornou nosso irmão em Cristo, para que atrás de cada irmão encontremos a ele. ${ }^{24}$

A vinda de Cristo a terra é ressignificada por Bonhoeffer quando ele coloca como uma das principais funções o fato de Cristo nos mostrar o outro através de sua vinda e sua vida. É a

\footnotetext{
21 BONHOEFFER, Dietrich. Resistência e submissão: cartas e anotações escritas na prisão. São Leopoldo: Editora Sinodal, 2003, p. 43.

22 BONHOEFFER, Dietrich, MALSCHITZKY, Harald. Prédicas e Alocuções, São Leopoldo: Editora Sinodal, 2007, p. 7.

23 BONHOEFFER, Dietrich. Resistência e submissão: cartas e anotações escritas na prisão. São Leopoldo: Editora Sinodal, 2003, p. 40.

${ }^{24}$ BONHOEFFER, Dietrich, MALSCHITZKY, Harald. Prédicas e Alocuções, São Leopoldo: Editora Sinodal, 2007, p. 38.
} 
imagem de um Cristo humanizado que se submete aos sofrimentos humanos e a tentativa constante de experienciar o sofrimento humano em carne e $\mathrm{osso}^{25}$.

A obra síntese de Bonhoeffer a este respeito é o já citado Vida em Comunhão. O livro de 1938 sintetiza percepções que Bonhoeffer já desenvolvia desde sua tese de doutorado. A comunhão (e o próprio cristianismo na visão do teólogo), portanto, partem do pressuposto de se relacionar com o outro a partir de Cristo. A obra, por ser escrita em um momento onde a sua comunidade de fé foi desfeita - e presa-, reflete como essa comunhão com o outro pode se manter em momentos de adversidade. Viver em comunhão não é viver entre cristãos uma vez que o lugar do cristão "não é na reclusão da vida monacal mas em meio aos inimigos"26. A vivência cristã deve e será feita além dos muros da igreja. Bonhoeffer não traz uma definição de mundo público ou esfera pública definida em sua obra. Compreendemos que a ideia de sair de si e publicizar as reflexões com seus irmãos de fé e, para além disso, com os não crentes, é uma forma de agir fora da vida devocional do indivíduo com Deus. Uma forma de agir no mundo público.

Nesse momento de solidão vivido pelo teólogo, ele ressalta constantemente a presença física dos irmãos em fé como algo essencial para ele. Relacionar-me com o outros é me relacionar com Cristo ao mesmo tempo em que me relacionar com Cristo é me relacionar com o outro. A definição que ele dá de comunhão é que ela pode ser feita exclusivamente por meio e em Jesus Cristo $^{27}$. Nessa obra, ele foca na relação criada entre um cristão e outra a partir da vivência sob a palavra, prática e fé cristã. Aparece como um elo estabelecido na comunidade cristã que se cria, fortalece e cresce a partir da mediação de Jesus Cristo. A comunhão não é prevista como uma relação que se estabelece com o outro fora da relação com Cristo em Vida em Comunhão. Ele define, na obra, dois tipos de relações que são estabelecidas entre os indivíduos. Uma relação, um amor ou uma comunhão podem ser pneumáticas, definida como espirituais ou anímicas, fundamentada no psíquico. ${ }^{28}$ Bonhoeffer não faz uma hierarquia entre o psíquico e o anímico, mas afirma que a comunhão cristã se distingue de todas as outras por ser criada pelo Espírito Santo. Prevê, com isso, que existem comunhões que não são de teor espirituais e que são estabelecidas entre aquilo que o pastor chama de "almas piedosas". Sua

\footnotetext{
${ }^{25}$ É importante citar a disputa de narrativas acerca da figura de Jesus Cristo presente no período. A ideia de desjudaização das igrejas e da teologia protestante passava por uma reinterpretação de Cristo como um a referência ariana e uma figura vencedora perante os judeus. Cf HESCHEL, Susannah. The Aryan Jesus: Christian Theologians and the Bible in Nazi Germany. Princeton: Princeton University Press, 2008.

${ }^{26}$ BONHOEFFER, Dietrich. Vida em comunhão. São Leopoldo: Sinodal, 2009, p. 9.

${ }^{27}$ Ibidem, p. 12.

${ }^{28}$ BONHOEFFER, Dietrich. Vida em comunhão. São Leopoldo: Sinodal, 2009, p. 21-29.
} 
crítica está voltada ao fato de que a relação fundamentada na fé cristã não pode ser baseada no amor ou na comunhão anímica pois estas tem como origem os instintos, forças e faculdades da alma humana e não o intermédio de Cristo.

Assim, Dietrich Bonhoeffer se preocupa em discutir sobre a relação dos humanos consigo mesmos em momentos de solidão. Ele não vê a solidão como algo que, em sua essência, é negativo. A relação que ele faz entre a comunhão entre os irmãos e solidão é apresentada no terceiro capítulo da obra.

\begin{abstract}
Nós reconhecemos: somente podemos ficar sozinhos se estivermos na comunhão, e somente quem está sozinho pode viver em comunhão. [...] Só na comunhão aprendemos a estar sozinhos no sentido correto; e somente na solidão aprendemos a viver de modo correto na comunhão. ${ }^{29}$
\end{abstract}

Há, portanto, uma relação direta entre solidão e comunhão para ele. A solidão aparece como pressuposto para que o indivíduo saiba lidar com e para com o outro. Lidar consigo mesmo é pré-requisito para lidar com o qualquer outro ser humano. Estar sozinho é uma condição imposta a todos os seres humanos, desde seu nascimento até sua própria morte. A comunhão só pode se formar porque várias pessoas carregadas de suas próprias solidões decidem se agrupar. ${ }^{30}$ A solidão é, por consequência, necessária dentro dessa perspectiva pois é nela que a comunhão diária do próprio indivíduo com Cristo se forma através do que define como os pilares da comunhão: a leitura da Palavra, a oração e a intercessão. Este último aspecto é fundamental pois é "na intercessão, seu rosto [do irmão], antes talvez estranho e insuportável, se transforma no rosto de um irmão pelo qual Cristo morreu, no rosto do pecador perdoado." ${ }^{\prime 1}$. Apesar de um exercício feito na solidão, é uma prática voltada para o outro na tentativa de se colocar no lugar dele.

Todavia, estar na solidão não é estar solitário. Estar com o outro é tido por Bonhoeffer como um dos principais serviços que o cristão pode realizar por outro. Não somente estar com o outro mas também estar pelo outro assim como o outro deve estar por mim. É uma relação empática que prevê a reciprocidade. No trecho de Resistência e Submissão citado anteriormente, Bonhoeffer prevê que a minha atuação pelo outro vem a partir da compaixão que desenvolvo pelas experiências do meu irmão. É interessante a utilização da palavra ‘irmão' nesse trecho. O teólogo utiliza o conceito ‘irmãos' de diferentes maneiras ao longo de

\footnotetext{
${ }^{29}$ Ibidem, p. 66.

${ }^{30}$ Ibidem, p. 67.

31 Ibidem, p. 72.
} 
suas produções. Em um primeiro momento, o irmão é o irmão na fé, irmão em Cristo, como transparece em Vida em Comunhão. No entanto, conforme sua resistência ao regime se torna mais violenta e se compromete na proteção de grupos que são perseguidos, o pastor passa a utilizar o conceito de irmãos para falar a respeito dos judeus, por exemplo. O irmão passa a ser o outro.

Ao permitir que os problemas do mundo interrompam os teólogos e os cristãos dentro de sua bolha religiosa, os cristãos passam a ver as questões que ocorrem no público como suas próprias questões. Veem-se responsáveis pelo mundo público e pelas coisas que os dizem respeito por se verem, também, como parte desse mundo e não apenas como um telespectador que vivencia, apenas, as experiências extra corpóreas ou espirituais. É algo que prevê uma ação consciente guiada, a priori, por Cristo. A consciência é, para ele, uma instância do ser humano que "clama pela unidade da existência humana consigo mesma",32, que impede a destruição do próprio ser. A consciência não pode, todavia, estar fundamentada na autonomia do próprio eu mas sim em Cristo. "A consciência libertada não é temerosa como aquela comprometida com a lei, mas amplamente aberta para o próximo e para as suas necessidades concretas." 33 . Priorizar o bem-estar, a segurança e, até mesmo, a vida do próximo é ter uma atitude responsável no mundo. Ter essa reação é reconhecer a culpa inerente ao ser humano em sua existência. Em Ética, escreve que "sou culpado de covarde silêncio quando deveria ter falado; sou culpado de hipocrisia e falta de veracidade diante da violência; sou culpado de falta de misericórdia e de renegar os mais pobres dos irmãos." ${ }^{\text {"4 }}$. Ser responsável é, em última instância, comprometer minha vida pela vida do outro. É saber que o que acontece além da minha vivência particular também me diz respeito e devo tomar partido nesse mundo público no qual estou inseridos.

\section{Um diálogo entre filosofia e teologia a partir de Hannah Arendt e Dietrich Bonhoeffer}

As explanações apresentadas sobre os pensamentos de cada intelectual abrem caminho para refletirmos sobre as possíveis interseções e distanciamento nas visões de ambos sobre política e ação no mundo público. Como apresentado, um dos objetivos deste ensaio é, além de apresentar essas relações, analisar como os conceitos de comunhão e amizade de ambos tem um princípio similar de elaboração.

\footnotetext{
${ }^{32}$ BONHOEFFER, Dietrich. Ética. São Leopoldo: Sinodal, 2008, p. 154.

${ }^{33}$ Ibidem, p. 155.

${ }^{34}$ Ibidem, p. 74.
} 
A primeira e mais latente das questões é que as compreensões de ambos se interceptam no que diz respeito à responsabilidade do indivíduo com os assuntos que ocorrem no mundo e à responsabilidade que tenho com o ser humano que, parecendo comigo ou não, está estabelecido na mesma comunidade política que eu. Arendt compreende a noção de amizade política como uma forma de se associar aos humanos e, a partir de nossas percepções de mundo, agir neste mundo do qual fazemos parte. É uma associação que prevê a noção de responsabilidade justamente pela compreensão que ela tem de amor mundi, essa consciência da responsabilidade e do potencial de ação que tenho para com o mundo.

Arendt prevê que a amizade política ocorre necessariamente na esfera pública. Ao exercer minha liberdade, ou seja, ao exercer a própria política, eu necessariamente estou vinculada ao outro pois o espaço de ação livre se constitui através da associação dos seres políticos. Bonhoeffer prevê a comunhão como uma relação que acontece, a princípio, na esfera privada, ou seja, na vida monacal ${ }^{35}$. É um vínculo estabelecido para a confissão, a intercessão, ou seja, assuntos vinculados ao particular da vida humana. Todavia, a questão que nos permite estabelecer um paralelo entre a análise de Bonhoeffer e de Arendt é que a comunhão, para ele, exige que o cristão, através da ligação íntima que constituiu com o outro através de Cristo tenha um comportamento ativo na esfera pública especialmente no que diz respeito a proteção do outro.

Compreende-se aqui, também, a igreja, as comunidades de fé e os seminários teológicos como espaços públicos de ação. Uma articulação de pastores como a ocorrida em 1933 com a Liga Pastoral de Emergência ${ }^{36}$ é a formação de um espaço de atuação pública dentro das igrejas que se forma através de relações privadas entre os membros daquela comunidade para que o mundo político seja palco para suas ações. A cena pública é definida por Arendt não como um espaço público em si, mas sim um espaço onde a liberdade pode aparecer ${ }^{37}$. Nesse contexto, portanto, a liberdade foi exercida por esses pastores tendo em vista a noção de responsabilidade que os impelia a agir.

\footnotetext{
35 Dietrich Bonhoeffer não pontua em seus escritos uma compreensão clara de esfera pública e esfera privada. Compreendemos que aquilo que diz respeito ao relacionamento do indivíduo com Deus, unicamente, é um aspecto privado.

${ }^{36}$ A Liga Pastoral de Emergência foi um grupo criado por iniciativa de Martin Niemoller com o objetivo de combater a cláusula ariana imposta à Igreja e a ingerência do Estado nazista na comunidade protestantes. Cf SILVA, Julio César Silveira da. Karl Barth: um chamado cristão a desobediência civil. 162 f. Dissertação (Mestrado em Ciências da Religião) - Pontifícia Universidade Católica de São Paulo, São Paulo, 2011, p. 49.

37 ARENDT, Hannah. A promessa da política. Rio de Janeiro: DIFEL, 2010, p. 178
} 
A noção de responsabilidade pelo mundo prevista por Arendt está atrelada a sua noção de amor mundi assim como a compreensão de Bonhoeffer do conceito está vinculada ao seu entendimento de Igreja e de vários aspectos que constituem o seu pensamento teológico. A responsabilidade, para Arendt, está interligada também à ideia de consciência, de poder conviver em paz consigo mesmo. "Não posso fazer certas coisas porque, depois de fazê-las, já não serei capaz de viver comigo mesma." 38 . Agir de forma responsável é agir no mundo público em prol da liberdade e do outro ou, como neste caso, não me submetendo às ações que comprometem a liberdade e o outro é uma ação que também tenho comigo mesmo. Um dos episódios fundamentais para a vida de Dietrich Bonhoeffer foi quando, ao estar em segurança nos Estados Unidos com o início da Segunda Guerra Mundial, escreve a seu amigo e teólogo Reinhold Nieburh dizendo que tinha a responsabilidade de voltar para a Alemanha nesse momento. ${ }^{39}$ Ter a consciência da responsabilidade do indivíduo com o outro e o comprometimento que você deve estar em unidade consigo mesmo é não se opor contra sua consciência pois toda "a ação contra a consciência está na linha da ação suicida da própria vida" 40 . Assim como em Arendt, para agir no mundo político, com o meu par, é necessário estar em unidade consigo. A comunhão cristã prevê a comunhão individual, na solidão, assim como a ação livre do indivíduo prevê o diálogo silencioso de mim comigo mesmo.

A solidão tem compreensão muito similar no escrito de ambos assim como sua necessidade para que a amizade política e a comunhão cristã se estabeleçam. Em Vida em Comunhão, Dietrich Bonhoeffer alerta para pessoas que "procuram a comunhão por medo de ficarem sozinhas. Por não suportarem a solidão, são impelidas a procurar a companhia de outras pessoas [assim como] cristãos que não conseguem lidar consigo mesmos" ${ }^{\text {"1 }}$. Se refugiar na comunhão cristã como forma de fugir de si mesmo é, para o pastor, uma forma de transformar a comunidade de fé em um sanatório espiritual. Lidar consigo é pré-requisito para qualquer um, na comunidade cristã ou fora dela. Arendt compreende o estar só como algo estritamente necessário para os indivíduos, inclusive no que diz respeito ao ato de pensar. Para ela, “o estar só significa que, apesar de estar sozinha, estou junto com alguém (isto é, eu

\footnotetext{
${ }^{38}$ Responsabilidade e Julgamento. Trad. Rosaura Eichenberg. Ed. Cia. Das Letras, São Paulo. Ed. Perspectiva. 2004, p. 162

${ }^{39}$ METAXAS, Eric. Bonhoeffer: Pastor, Mártir, Profeta, Espião. Belo Horizonte: Nelson, 2012, p. 285.

${ }^{40}$ BONHOEFFER, Dietrich. Ética. São Leopoldo: Sinodal, 2008, p.154.

${ }^{41}$ BONHOEFFER, Dietrich. Vida em comunhão. São Leopoldo: Sinodal, 2009, p. 57.
} 
mesma)"42. Assim como, em Bonhoeffer, a solidão precede a comunhão, em Arendt, a solidão precede a amizade.

Outro ponto onde podemos estabelecer um interessante diálogo entre os autores é a centralidade que ambos dão a palavra e ao discurso como formas de estabelecer a amizade política e a comunhão cristã. Bonhoeffer fala que a característica da solidão é o silêncio, a espera pela resposta divina. Na comunhão, contudo, o falar é o eixo central. Estabeleço minha relação com o outro através da palavra e é, através desse mesmo instrumento, que ajo além da minha própria comunidade. O teólogo afirma em Resistência e Submissão que "a coragem de manifestar a própria opinião só pode brotar do livre senso de responsabilidade do homem livre" ${ }^{43}$. Partindo disso, se sentir responsável não basta. É necessário manifestar essa compreensão através do discurso e através de uma atuação ativa no mundo.

Quando Hannah Arendt afirma que as questões só são humanas quando são objetos de discurso, observa-se a centralidade do ato de falar - e da compreensão do falar como ação presente em sua obra. Quando ela afirma, no entanto, que as coisas podem nos afetar mas que só se tornam humanas quando discutimos com o próximo, podemos fazer um elo entre o discurso e a amizade política proposto Hannah Arendt. Ter um problema, uma ideia, uma solução não faz com que essa questão se torne uma questão humana mas sim trazê-la a esfera pública através da discussão com o próximo.

Dietrich Bonhoeffer e Hannah Arendt foram contemporâneos e experimentaram, cada um em sua forma, o totalitarismo nazista. Os conceitos centrais na análise foram cunhados pelos autores em diferentes momentos históricos - Bonhoeffer, no efervescer da Alemanha Nazista e Arendt, no Pós-Guerra - mas ambos centrados na discussão (e oposição) ao totalitarismo na Europa assim como na capacidade de ação dos indivíduos tendo em vista o governo que cerceava as atuações dos indivíduos no mundo público. Arendt, ao diferenciar um governo totalitário de um governo ditatorial, demonstra que o último pretende minar a atuação na esfera pública enquanto o primeiro, além disso, se introjeta na esfera privada a fim de minar as próprias reações espontâneas - e humanas - entre os indivíduos ${ }^{44}$. Sabendo disso, ao observarmos que o conceito de comunhão depende inteiramente das relações estabelecidas

\footnotetext{
${ }^{42}$ ARENDT, Hannah. Responsabilidade e Julgamento. Trad. Rosaura Eichenberg. Ed. Cia. das Letras, São Paulo. Ed. Perspectiva. 2004, p.16.

${ }^{43}$ BONHOEFFER, Dietrich. Resistência e submissão: cartas e anotações escritas na prisão. São Leopoldo: Editora Sinodal, 2003, p. 31.

${ }^{44}$ ARENDT, Hannah. Compreender: formação, exílio e totalitarismo; ensaios (1930-1954). Rio de Janeiro: Companhia das Letras, 2008, p. 375.
} 
na esfera privada, o totalitarismo tentaria deixar o indivíduo não em solidão, no sentido de estar só consigo mesmo, mas, sim solitário, isolado. A amizade política e a comunhão cristã aparecem, portanto, como oponentes radicais aos ideais totalitários.

Em A Promessa da Política, Hannah Arendt compara a destruição do mundo público, os sombrios tempos que os seres humanos enfrentam, a um deserto. Entender o mundo público moderno como um espaço desertificado, ou seja, onde as relações não se fundem e não se firmam, dificultando e, até mesmo, impossibilitando a ação é uma metáfora que nos faz pensar sobre os porquês e as (ainda existentes) possibilidades do totalitarismo no mundo moderno. Essa desertificação do mundo político moderno se dá de diversas formas, mas isso não nos obriga a ceder e morrer de sede ao caminharmos por esse espaço. Os oásis são "esferas da vida que existem independentemente, ao menos em larga medida, das condições políticas" ${ } 45$. Esses refrigérios, mais do que porto de descanso para o caminhante que enfrenta o calor e as adversidades do deserto, são um meio de esperança para aqueles que, mesmo estando neste deserto, não o percebe ou não quer agir em meio a ele.

Nossa compreensão apresentada de comunhão cristã e amizade política podem ser compreendidas como esses oásis em meio ao deserto político da modernidade. São espaços de esperança, renovação e fluidez das águas. As relações estabelecidas com o próximo assim também o são, especialmente se voltadas para a sede daqueles que necessitam. O indivíduo que, ao andar pelo mundo político arrastado pela aridez das relações modernas ou pelo sufocante calor das cobranças feitas ao ser humano moderno, é capaz de encontrar homens e mulheres que se associam para modificar as condições adversas impostas a eles. Encontra-se aí não apenas formas de relaxar, mas formas de viver em um mundo onde é necessário o compartilhar e o tomar consciência da sua responsabilidade frente àquilo se faz presente. $\mathrm{O}$ oásis, por si só, não transforma o deserto. É o compartilhamento, é o se doar pelo outro e pelo mundo em um espaço catastrófico que podem fazer dessas esferas da vida - a união através da fé, através da política, através dos interesses públicos - esferas de uma ação responsável para a transformação do mundo no qual nós, seres políticos, fazemos parte.

\footnotetext{
${ }^{45}$ ARENDT, Hannah. A promessa da política, trad. Rio de Janeiro: Difel, 2008, p. 267.
} 


\section{Bibliografia}

ALVES AGUIAR, Odílio. A amizade como amor mundi em Hannah Arendt. O que nos faz pensar, [S.1.], v. 19, n. 28, p. 131-144, dec. 2010. ISSN 0104-6675. Disponível em: $<$ http://www.oquenosfazpensar.fil.puc-rio.br/index.php/oqnfp/article/view/315>. Acesso em: 31 jan. 2019, P. 139.

ARENDT, Hannah. A Condição Humana. Tradução de Roberto Raposo. Rio de Janeiro: Forense, 1983.

- A dignidade da política. Rio de Janeiro: Relume-Damará, 1993.

. Entre o Passado e Futuro. 6a ed. São Paulo: Perspectiva. 2007.

. A promessa da política. Rio de Janeiro: Difel, 2008.

. Compreender: formação, exílio e totalitarismo; ensaios (1930-1954).

Rio de Janeiro: Companhia das Letras, 2008.

Homens em Tempos Sombrios. Tradução de Denise Bottmann. São Paulo: Companhia das Letras, 1987.

. Origens do totalitarismo: antissemitismo, imperialismo, totalitarismo.

Rio de Janeiro: Companhia das Letras, 2013.

KOHN, Jerome. Responsabilidade e julgamento. São Paulo: Companhia das Letras, 2004.

BARNETT, Victoria. For the Soul of the People: Protestant protest against Hitler. Oxford: Oxford University Press, 1998.

BAUMAN, Zygmunt. Amor líquido: sobre a fragilidade dos laços humanos. Rio de Janeiro: Jorge Zahar Editor, 2004.

BETHGE, Eberhard. Dietrich Bonhoeffer: a biography. Minnesota: Fortress Press, 1999.

BONHOEFFER, Dietrich, MALSCHITZKY, Harald. Prédicas e Alocuções, São Leopoldo: Editora Sinodal, 2007.

Ética. São Leopoldo: Sinodal, 2008.

. Vida em comunhão. São Leopoldo: Sinodal, 2009

. Resistência e submissão: cartas e anotações escritas na prisão. São Leopoldo: Editora Sinodal, 2003.

. Sanctorum communio: A theological study of the sociology of

the church. Minneapolis: Fortress Press, 1998. 
CALDAS, Carlos. Dietrich Bonhoeffer e a teologia pública no Brasil, São Paulo: Garimpo, 2016.

METAXAS, Eric. Bonhoeffer: pastor, mártir, profeta, espião. São Paulo: Mundo Cristão, 2011.

NICOSIA, Francis R.; STOKES, Lawrence D. (Org.). Germans against Nazism: nonconformity, opposition and resistance in the Third Reich: essays in honour of Peter Hoffmann. New York: Berg Publishers Ltd, 1990. 